\title{
Yersinia pestis
}

National Cancer Institute

\section{Source}

National Cancer Institute. Yersinia pestis. NCI Thesaurus. Code C86860.

A species of facultatively anaerobic, Gram negative, rod shaped bacteria in the phylum

Proteobacteria. This species is motile, positive for coagulase and fibrinolysin and negative for urease, indole, ornithine decarboxylase, oxidase, and pyrazinamidase. Some strains are able to ferment melibiose but none can metabolize sorbose, rhamnose, cellobiose, sucrose, or sorbitol. Y. pestis is found in rodents and fleas and is a pathogen that can cause pneumonic, septicemic and bubonic plague types in humans. 